\title{
Kendali Logika Fuzzy Pada Robot Line Follower
}

\author{
Line Follower Robot with Fuzzy Logic Control \\ David \\ STMIK Pontianak \\ E-mail: davidliauw@gmail.com
}

\begin{abstract}
Abstrak
Pada Penelitian ini, dirakit dan dikodekan program sebuah robot line follower menggunakan sensor cahaya. Logika fuzzy digunakan sebagai kendali dalam mengidentifikasi kecepatan robot agar dapat bergerak dan berjalan sesuai dengan jalur/garis pita berwarna hitam. Metode yang digunakan adalah metode Mindstorms dengan robot line follower berbasiskan microcontroller seri ATMegal6. Metode ini adalah metode sederhana yang terdiri dari empat tahapan yaitu mencari ide untuk robot, membangun robot, memprogram robot dan dokumentasi. Pemrograman robot dengan menggunakan bahasa pemrograman BASCOM AVR digunakan untuk mendapatkan program yang bekerja terbaik. Pengujian dilakukan terhadap penggunaan sensor, motor DC dan ketelitian gerak line follower. Robot line follower yang dibuat dengan menggunakan microcontroller ATMegal6 dapat melakukan scanning jalur pita berwarna hitam dan laju pergerakan berdasarkan kendali logika fuzzy.
\end{abstract}

Kata Kunci - Robot line follower, Microcontroller, Logika Fuzzy, Sensor Cahaya, Kecepatan.

\begin{abstract}
In this study, assembled and coded program a line follower robot using a light sensor. Fuzzy logic is used as a control in order to identify the speed of the robot can move and run in accordance with the path / line black ribbon. The method used is a method Mindstorms robot line follower based microcontroller ATmegal6 series. This method is a simple method that consists of four stages, namely looking for ideas for robots, building robots, robot programming and documentation. Programming robots using BASCOM AVR programming language used to get a program that works best. Tests conducted on the use of sensors, DC motors and precision motion line follower. Line follower robot created using ATmegal6 microcontroller can scan a black ribbon path and rate of movement is based on fuzzy logic control.
\end{abstract}

Keywords - Line Follower Robot, Microcontroller, Fuzzy Logic, Light Censor, Velocity.

\section{PENDAHULUAN}

Robot adalah salah satu perkembangan teknologi yang saat ini berkembang dalam dunia khususnya di Indonesia. Line Follower merupakan salah satu teknologi yang berkembang dalam dunia saat ini. Line Follower adalah robot yang berjalan mengikuti garis, dan di dalamnya terdapat sebuah Integrated Circuit yang berisi pemrograman untuk menjalankannya. Perlu penerapan pada pemrogramannya bagaimana cara line follower tersebut bisa berjalan, kenapa juga bisa berjalan mengikuti garis, serta apa yang membuat line follower tersebut bisa berjalan.

Penerapan pemrograman pada line follower ini dimaksudkan agar pengguna dapat menggunakan robot khususnya pada line follower. Penelitian ini akan membahas tentang penerapan pemrograman, dengan tujuan mencoba membangun robot untuk berjalan menggunakan program. Penerapan program tersebut juga memerlukan cara bagaimana cara 
pemrogramannya, supaya line follower tersebut dapat berjalan tepat mengikuti garis. Kenapa diperlukan penerapan pemrograman, dan mengapa diperlukan pemrograman dalam menjalankan line follower tersebut dan bagaimana cara pengimpletasikannya.

Dalam penelitian Sulistiyo (2009), navigasi robot menggunakan algoritma fuzzy. Proses fuzzy yang dilakukan meliputi fuzzifikasi, evaluasi rule dan defuzzijikasi. Dengan menggunakan algoritma ini robot dapat bergerak mengikuti jalur [1]. Dwisaputra, dkk. (2011) melakukan penelitian dengan sistem kontrol fuzzy logic robot yang mampu menjaga keseimbangan sambil mengikuti garis. Kemampuan robot mengikuti garis hanya pada garis lurus dan belokan yang berupa radius [2]. Farooq, dkk.(2014) melakukan penelitian bahwa kontrol logika fuzzy lebih baik pada robot guna kelancaran dalam mengikuti jalur yang diinginkan dan waktu yang dibutuhkan lebih cepat dalam menyelesaikan trek [3].

Robot line follower berbasis mikrokontroler dirancang dan dibuat agar dapat melakukan fungsi berjalan mengikuti garis yang berwarna hitam. Logika fuzzy (fuzzy logic) digunakan untuk mengidentifikasi robot supaya bisa bergerak dan berjalan sesuai keinginan seperti robot yang berjalan menggunakan kaki atau menggunakan ban. Kendali fuzzy logic memberikan alternatif lain dalam sistem kendali. Dalam kendali fuzzy logic tidak diperlukan model matematika dari sistem karena kendali fuzzy logic bekerja berdasarkan rule-rule yang diekstrak sesuai dengan pemikiran dan pengetahuan manusia baik sebagai operator atau ahli. Penelitian yang telah dilakukan mengenai penggunaan metode fuzzy logic pada sistem pengontrolan yaitu aplikasi kendali fuzzy logic untuk pengaturan pergerakan motor.

\section{METODE PENELITIAN}

Bentuk Penelitian yang digunakan adalah studi literatur dan riset eksperimental. Perancangan tidak harus menyerupai bentuk asli dari alat yang ditiru, hanya langkah atau cara kerja dari alat yang tersebut. Pengumpulan data sekunder akan digunakan pada penelitian ini. Data sekunder merupakan sumber data penelitian yang diperoleh peneliti secara tidak langsung melalui media perantara (diperoleh dan dicatat pihak lain). Data sekunder umumnya berupa bukti, catatan atau laporan historis yang telah tersusun dalam arsip yang dipublikasikan dan tidak dipublikasikan. Teknik pengumpulan data yang dilakukan penulis adalah studi literatur. Studi literatur dilakukan dengan mengumpulkan teori dari buku, media, pakar ataupun dari hasil penelitian orang lain yang bertujuan yang berhubungan dengan robot line follower, baik dari segi perangkat keras dan perangkat lunak. Metode yang diterapkan adalah metode Mindstorms. Empat tahap utama dalam metode Mindstorms yang memandu proyek pembuatan robot line follower, yaitu: Mendapatkan ide untuk robot, Membangun robot, Memprogram robot, dan Mendokumentasikan robot[4]. Pengujian robot lebih ditekankan pada perangkat lunak (software) [4].

\section{HASIL DAN PEMBAHASAN}

Pembahasan masalah berorientasi pada penerapan program, dan cara penerapan program pada line follower jika terjadi error pada line follower seperti line follower berjalan mengikuti garis hitam yang dibuat oleh selotip berwarna hitam dengan ukuran $1,5 \mathrm{~cm}$. Penerapan program adalah program yang dibuat untuk menjalankan robot menggunakan kecerdasan buatan. Penerapan program line follower menggunakan logika 1 dan 0 . Dengan tiga buah sensor dan jalur yang dibuat dengan selotip warna hitam. Line follower akan berjalan mengikuti sesuai garis dengan sensor, sensor akan membaca warna yang dipantulkan cahaya yang kemudian membaca warna hitam dan warna putih. 
Dengan menggunakan metode ini implementasi dan pembuatan robot dapat dilakukan lebih efektif terutama dalam konstruksi dan pemrograman. Empat tahap utama dalam metode protipe yang memandu pembuatan robot dan implementasi.

a. Perancangan Sensor Robot Line Follower.

b. Perancang Tubuh Robot Line Follower.

c. Logika Fuzzy Robot.

d. Pemrograman Robot.

Di dalam perancangan robot line follower memiliki PEAS (Performance Environment Actuators Sensors) yaitu [5]:

1. Performance Measure : Berjalan mengikuti garis

2. Environment : Garis hitam

3. Actuators : Motor DC

4. Sensor : Sensor Cahaya

Tahap awal dalam implementasi adalah merancang sebuah robot line follower. Desain sebuah robot merupakan dasar dalam memulai proyek pembuatan robot, desain proses pembangunan robot agar fokus pada fungsi robot supaya lebih terarah dan tujuan dari proyek ini akan lebih jelas.

Setelah identifikasi robot telah terpenuhi, maka akan memasuki tahap selanjutnya yaitu merancang robot. Perancangan robot akan dilakukan dengan proses trial and error. Proses ini akan lebih mengarah ke pembangunan bagian-bagian berbeda pada robot untuk mendapatkan struktur robot yang diinginkan. Setelah struktur fisik robot, pengujian akan dilakukan untuk memastikan bahwa bagian yang telah dibangun dapat berfungsi sesuai tujuan.

Perancang robot line follower ada dua tahap yaitu perancang sensor dan perancangan tubuh robot line follower seperti contoh pada gambar 1 .

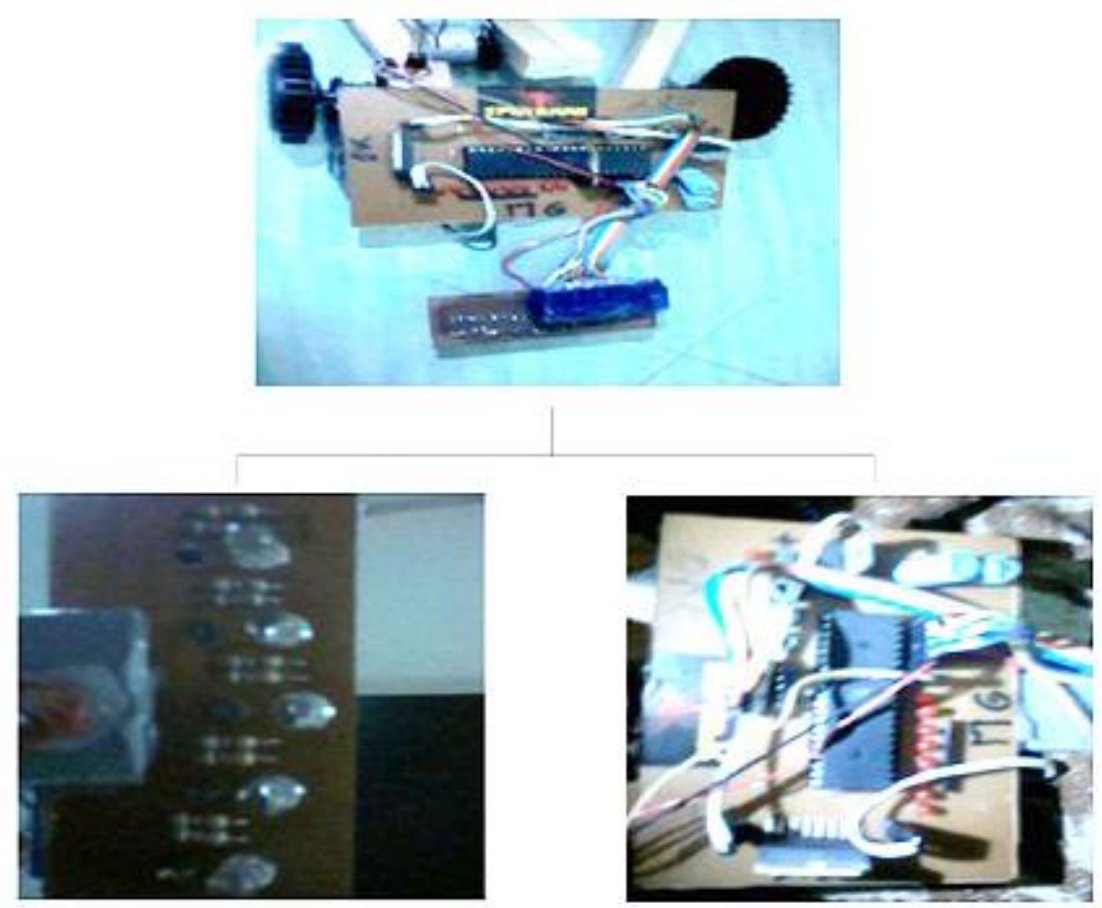

Gambar 1. Struktur perancangan robot line follower 


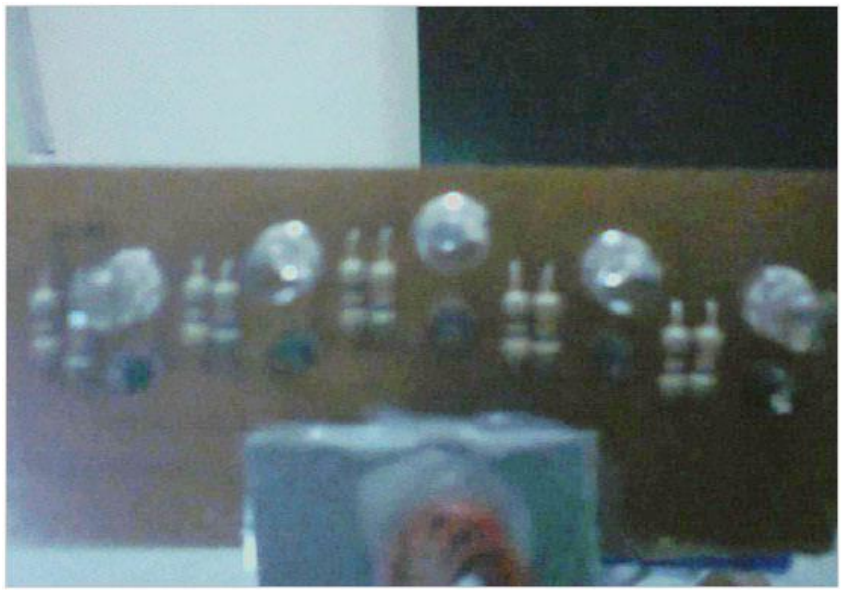

Gambar 2. Pemasangan keseluruhan sensor line follower

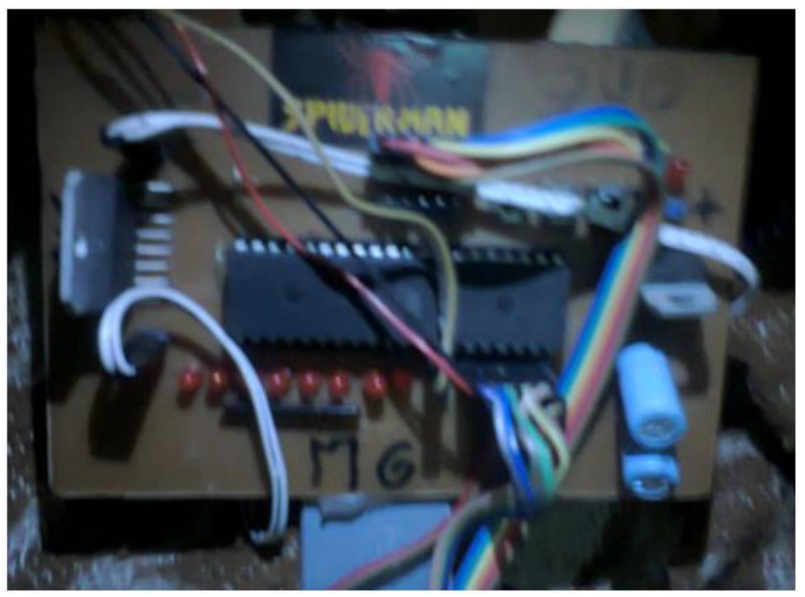

Gambar 3. hasil pemasangan tubuh line follower

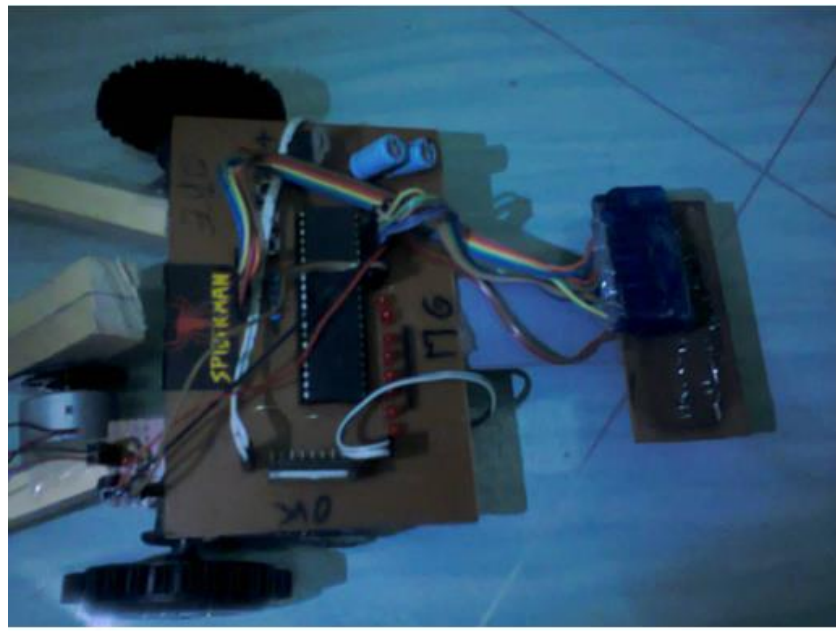

Gambar 4. Hasil pemasangan line follower 
Citec Journal, Vol. 3, No. 1, November 2015 - Januari 2016

Pada penelitian ini fuzzyline follower diperlukan untuk menjalankan robot line follower. Fuzzy line follower adalah fuzzy pada kecepatan robot line follower [6]. Pada hitung fuzzy ini input dari robot yang akan diubah menjadi himpunan sangat lambat, lambat, sedang atau cepat.

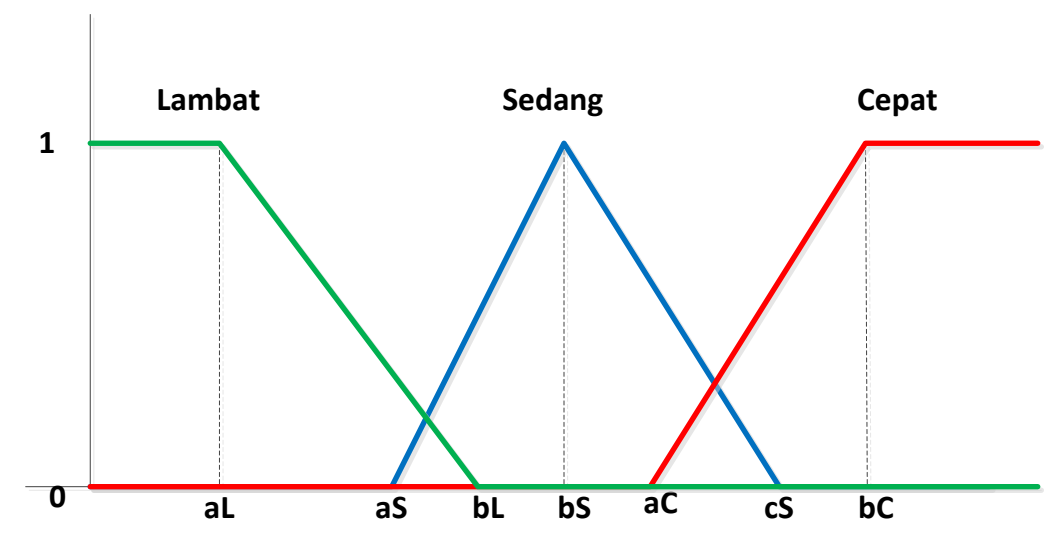

Gambar 5. Fuzzy hitung kecepatan
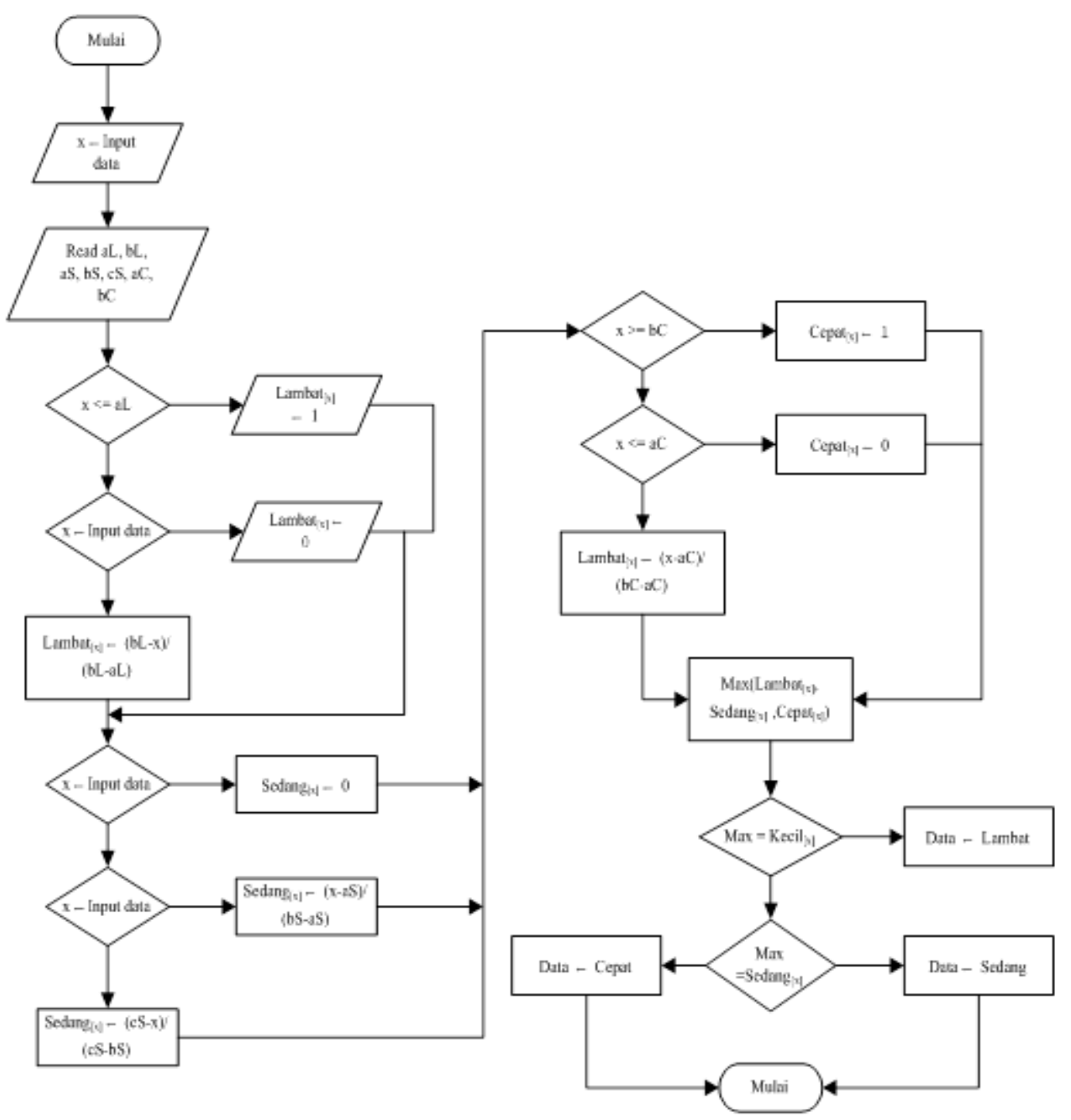

Gambar 6. Flowchart Kecepatan line follower 
Pada penelitian ini fuzzy line follower diperlukan untuk menjalankan robot line follower. Fuzzy line follower adalah fuzzy pada kecepatan robot line follower. Logika line follower ada pada tabel 1.

Tabel 1. Logika sensor line follower

\begin{tabular}{ccccccc}
\hline Sensor A & Sensor B & Sensor & & & \multicolumn{2}{c}{ Motor } \\
\hline 1 & 0 & 0 & 0 & 0 & $\begin{array}{l}\text { Motor } \\
\text { Kanan }\end{array}$ & Motor Kiri \\
\hline 0 & 1 & 0 & 0 & 0 & 1 & 0 \\
\hline 0 & 0 & 1 & 0 & 0 & 1 & 0 \\
\hline 0 & 0 & 0 & 1 & 0 & 0 & 1 \\
\hline 0 & 0 & 0 & 0 & 1 & 0 & 1 \\
\hline
\end{tabular}

Dari tabel 1, logika line follower adalah jika sensor A atau sensor B terbaca bernilai 1 maka nilai motor kanan adalah 1 , dan nilai motor kiri adalah 0 . Line follower akan berbelok ke kanan. Jika sensor D atau sensor E terbaca bernilai 1 maka nilai motor kanan adalah 0 , dan nilai motor kiri adalah 1. Line follower akan berbelok ke kiri. Jika sensor $\mathrm{C}$ terbaca bernilai 1 maka nilai motor kiri dan motor kanan adalah 1. Line follower akan berjalan lurus. Seperti pada gambar 7 .

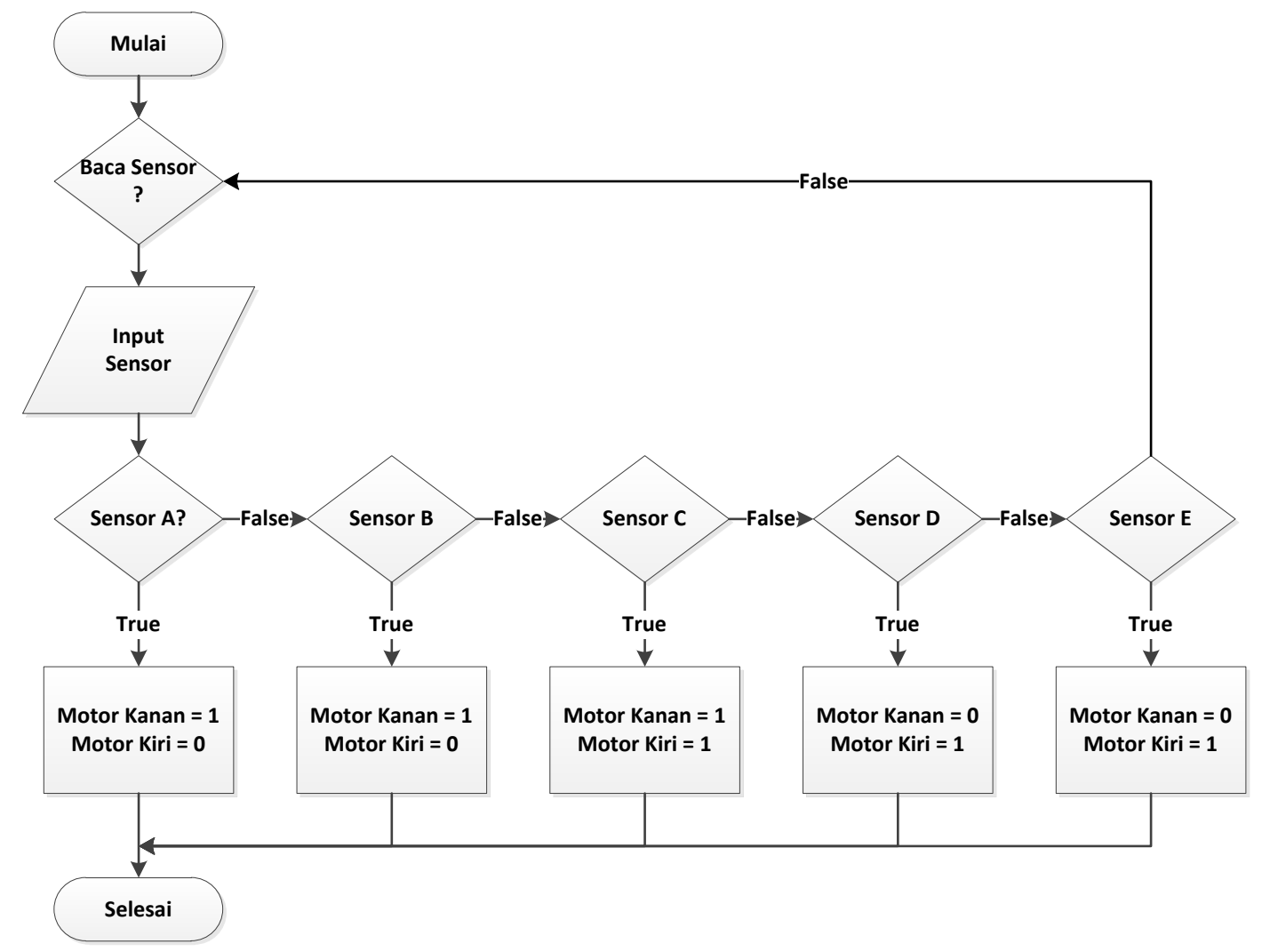

Gambar 7. flowchart logika line follower 
Citec Journal, Vol. 3, No. 1, November 2015 - Januari 2016

Program untuk menjalankan robot line follower dengan flowchart sebagai berikut:

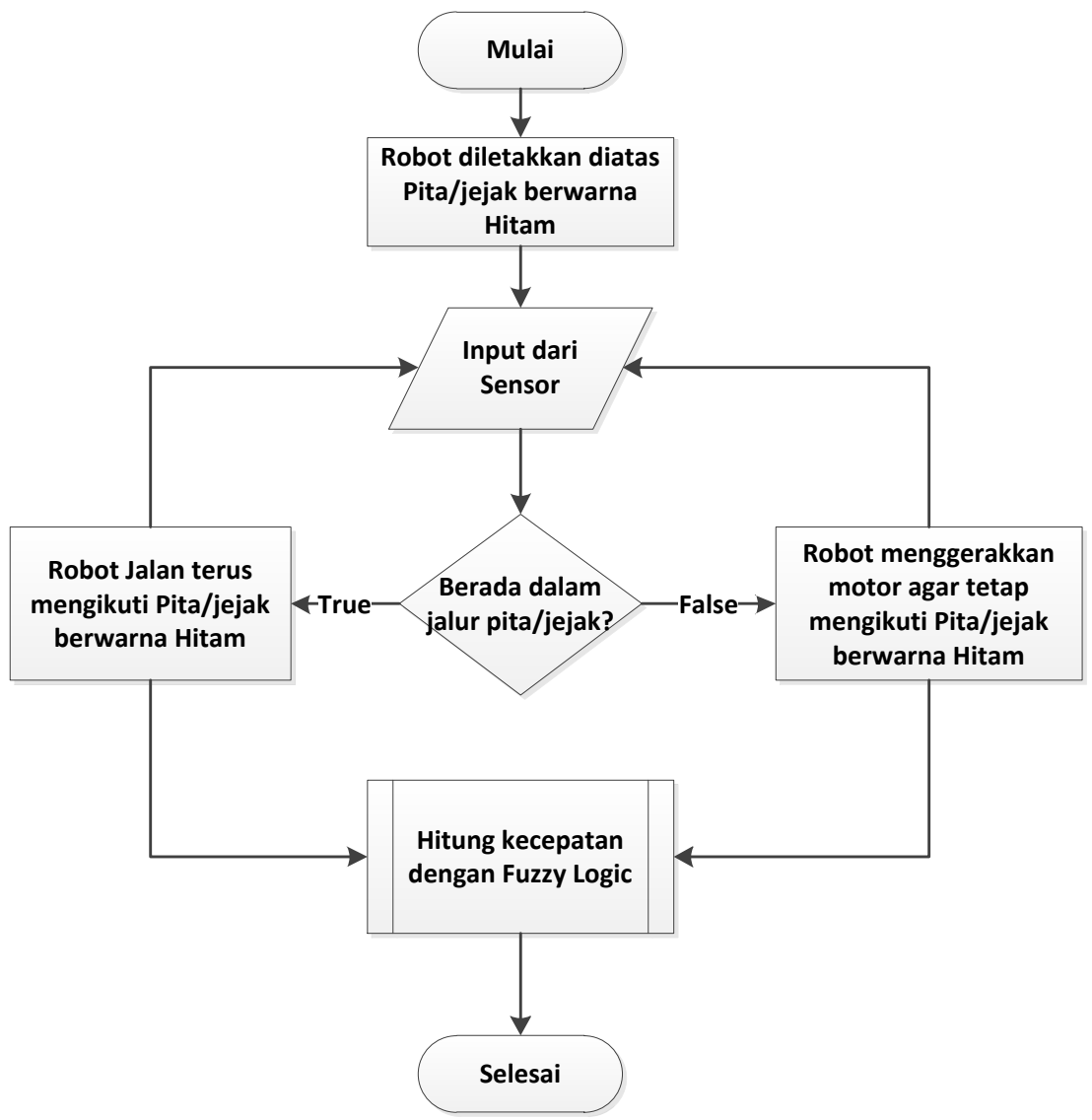

Gambar 8. Flowchart program BASCOM AVR line follower

Pengujian dilakukan dengan menguji sensor, sensor dapat menerima cahaya dengan baik. Sensor digunakan untuk robot line follower.

Pada pengujian ini sensor di uji kepekaannya terhadap cahaya. Dengan melakukan percobaan dengan mencoba jarak dekat hingga jarak jauh untuk mendapatkan hasil seperti pada tabel 2:

Tabel 2. Pengujian sensor

\begin{tabular}{ccc}
\hline Sensor & Jarak sensor dengan garis & Sensor terbaca \\
\hline & Tahap Pertama & \\
\hline Sensor A & $0,25 \mathrm{~cm}$ & Sangat Cukup \\
\hline Sensor B & $0,25 \mathrm{~cm}$ & Sangat Cukup \\
\hline Sensor C & $0,25 \mathrm{~cm}$ & Sangat Cukup \\
\hline Sensor D & $0,25 \mathrm{~cm}$ & Sangat Cukup \\
\hline Sensor E & $0,25 \mathrm{~cm}$ & Sangat Cukup \\
\hline & Tahap Kedua & \\
\hline Sensor A & $0,5 \mathrm{~cm}$ & Cukup \\
\hline Sensor B & $0,5 \mathrm{~cm}$ & Cukup \\
\hline Sensor C & $0,5 \mathrm{~cm}$ & Cukup \\
\hline Sensor D & $0,5 \mathrm{~cm}$ & Cukup \\
\hline Sensor E & $0,5 \mathrm{~cm}$ & Cukup \\
\hline
\end{tabular}


Tabel 2. (lanjutan)

\begin{tabular}{lll}
\hline & Tahap Ketiga & \\
\hline Sensor A & $1 \mathrm{~cm}$ & Cukup \\
\hline Sensor B & $1 \mathrm{~cm}$ & Cukup \\
\hline Sensor C & $1 \mathrm{~cm}$ & Cukup \\
\hline Sensor D & $1 \mathrm{~cm}$ & Cukup \\
\hline Sensor E & $1 \mathrm{~cm}$ & Cukup \\
\hline & Tahap Keempat & \\
\hline Sensor A & $1,5 \mathrm{~cm}$ & Cukup \\
\hline Sensor B & $1,5 \mathrm{~cm}$ & Cukup \\
\hline Sensor C & $1,5 \mathrm{~cm}$ & Cukup \\
\hline Sensor D & $1,5 \mathrm{~cm}$ & Cukup \\
\hline Sensor E & $1,5 \mathrm{~cm}$ & Cukup \\
\hline & Tahap Kelima & \\
\hline Sensor A & $2 \mathrm{~cm}$ & Jauh \\
\hline Sensor B & $2 \mathrm{~cm}$ & Jauh \\
\hline Sensor C & $2 \mathrm{~cm}$ & Jauh \\
\hline Sensor D & $2 \mathrm{~cm}$ & Jauh \\
\hline Sensor E & $2 \mathrm{~cm}$ & Jauh \\
\hline & Tahap Keenam & \\
\hline Sensor A & $2,5 \mathrm{~cm}$ & Jauh \\
\hline Sensor B & $2,5 \mathrm{~cm}$ & Jauh \\
\hline Sensor C & $2,5 \mathrm{~cm}$ & Jauh \\
\hline Sensor D & $2,5 \mathrm{~cm}$ & Jauh \\
\hline Sensor E & $2,5 \mathrm{~cm}$ & Jauh \\
\hline & Tahap Ketujuh & \\
\hline Sensor A & $3 \mathrm{~cm}$ & Sangat Jauh \\
\hline Sensor B & $3 \mathrm{~cm}$ & Sangat Jauh \\
\hline Sensor C & $3 \mathrm{~cm}$ & Sangat Jauh \\
\hline Sensor D & $3 \mathrm{~cm}$ & Sangat Jauh \\
\hline Sensor E & $3 \mathrm{~cm}$ & \\
\hline & & Sangat Jauh \\
\hline
\end{tabular}

Dari pengujian pada tabel di atas, sensor line follower dapat digunakan pada tahap ketiga sampai kelima. Sensor dapat digunakan pada jarak $0,5 \mathrm{~cm}$ sampai $1,5 \mathrm{~cm}$ dari garis hitam. Sensor akan dibuat dengan jarak antara 0,5 sampai $1,5 \mathrm{~cm}$. Secara keseluruhan sensor dapat digunakan.

Pengujian dilakukan dengan menguji Driver motor DC, menguji Driver Motor DC dan Motor DC dapat digunakan untuk merancang sebuah robot line follower. Pada Rangkaian ini terdapat sebuah IC A102J sebagai driver motor DC dan dua buah motor DC yang berfungsi menggerakkan pintu otomatis. Dengan melakukan sebuah percobaan dengan memberi input 0 atau 1 pada IC A102J didapatkan hasil seperti tabel 3:

Tabel 3. Rangkaian Driver Motor

\begin{tabular}{cccc}
\hline & PIN A102J & & \multirow{2}{*}{ Kondisi Motor } \\
\hline Enable 1 & Input 1 & Input 2 & \\
\hline 0 & 0 & 0 & Diam \\
\hline 1 & 0 & 0 & Diam \\
\hline 0 & 1 & 0 & Diam \\
\hline 0 & 0 & 1 & Diam \\
\hline 1 & 1 & 1 & Diam \\
\hline 1 & 1 & 0 & Putar Kanan \\
\hline 1 & 0 & 1 & Putar Kiri \\
\hline
\end{tabular}


Citec Journal, Vol. 3, No. 1, November 2015 - Januari 2016

Tabel 3. (lanjutan)

\begin{tabular}{cccc}
\hline Enable 2 & Input 1 & Input 2 & Kondisi Motor \\
\hline 0 & 0 & 0 & Diam \\
\hline 1 & 0 & 0 & Diam \\
\hline 0 & 1 & 0 & Diam \\
\hline 0 & 0 & 1 & Diam \\
\hline 1 & 1 & 1 & Diam \\
\hline 1 & 1 & 0 & Putar Kanan \\
\hline 1 & 0 & 1 & Putar Kiri \\
\hline
\end{tabular}

Melihat dari data di atas, dapat diketahui bahwa kaki enable harus memiliki tegangan high agar dapat memutarkan motor. Putaran arah motor ditentukan oleh kaki input 1 dan input 2. Secara keseluruhan, rangkaian driver motor DC siap untuk digunakan.

Pengujian robot akan difokuskan pada jalannya robot line follower. Program yang baik akan menghasilkan robot yang bekerja maksimal pula. Perubahan pada kode program mungkin terjadi pada saat proses pengujian. Bentuk robot juga akan disesuaikan dengan cara kerja program yang disuntikkan ke dalam robot. Oleh karena itu pengujian dilakukan dengan menggunakan pengulangan jalannya robot line follower. Tahap yang dilakukan adalah pengujian proses kerja robot line follower (tabel 4).

Tabel 4. Pengujian robot line follower

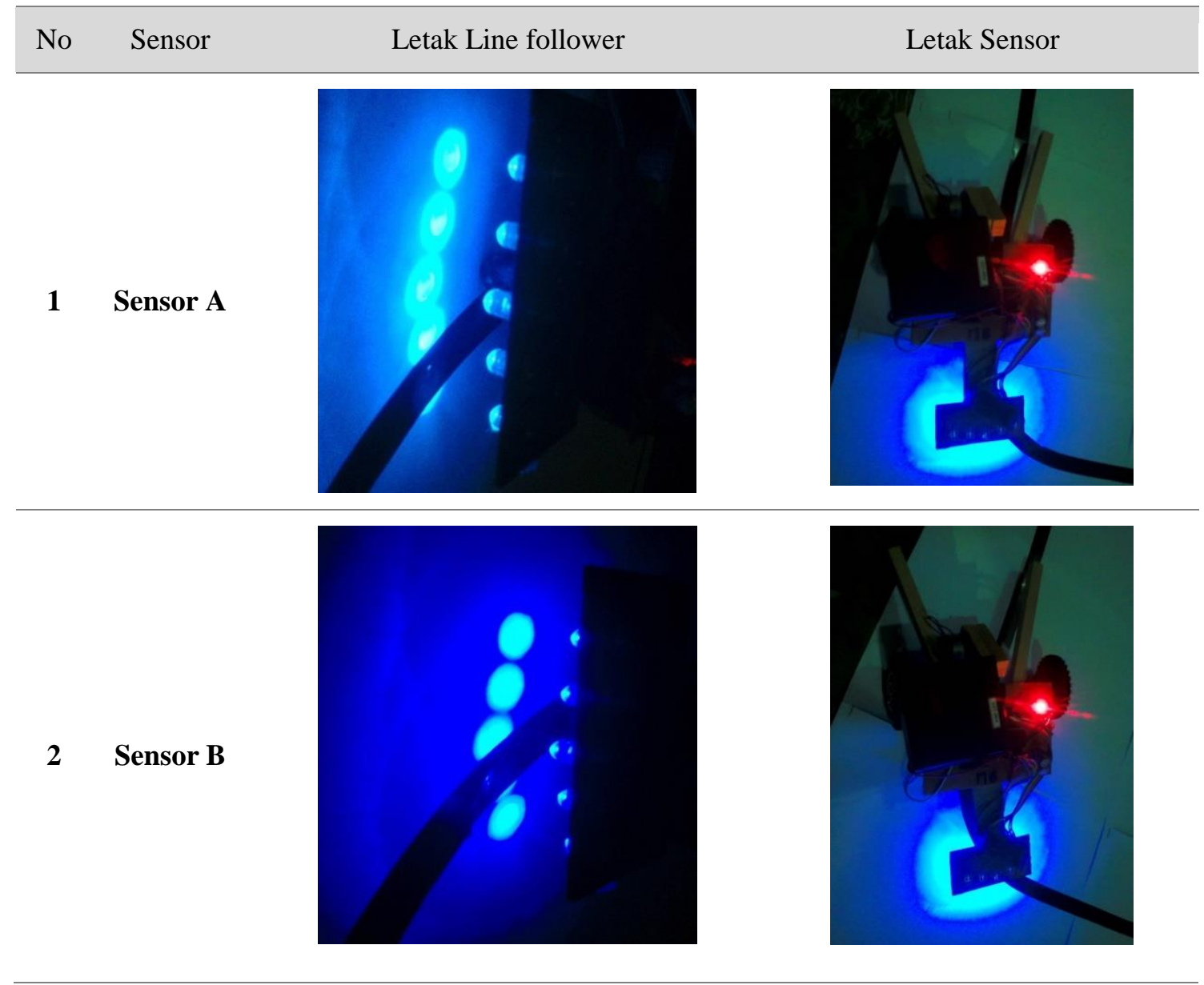


Tabel 4. (lanjutan)

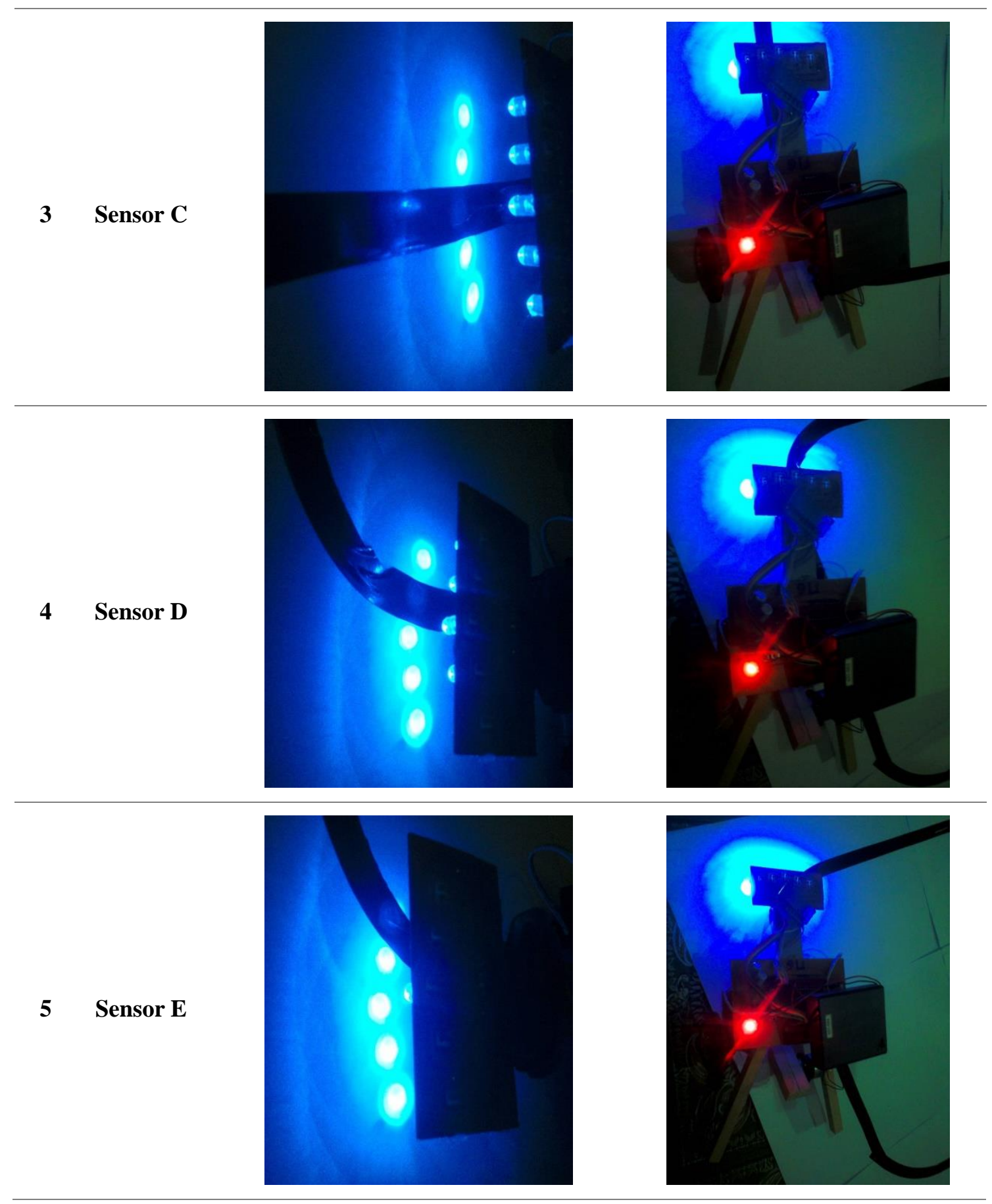

Pengujian dilakukan dengan menemukan sensor kepada garis secara berulang. Sensor dapat bekerja dengan baik. Apabila bekerja dengan sempurna. Selanjutnya pengujian pada robot line follower dengan menjalankan pada lintasan. Hasil pengujian dapat dilihat pada tabel 5 di bawah ini. 
Citec Journal, Vol. 3, No. 1, November 2015 - Januari 2016

Tabel 5. Pengujian line follower pada lintasan

\begin{tabular}{ccc}
\hline No. & $\begin{array}{c}\text { Jumlah Lap } \\
\text { Lintasan }\end{array}$ & Hasil \\
\hline 1 & 1 & Berjalan dengan baik \\
\hline 2 & 2 & Berjalan dengan baik \\
\hline 3 & 3 & Berjalan dengan baik \\
\hline 4 & 4 & Berjalan dengan baik \\
\hline 5 & 5 & Berjalan dengan baik \\
\hline
\end{tabular}

\section{KESIMPULAN}

Berdasarkan seluruh pengujian dan uraian laporan perancangan Robot line follower dengan kendali logika fuzzy, dapat diambil kesimpulan yang mungkin dapat dijadikan acuan dalam perancangan robot. Robot dapat bekerja sesuai dengan program yang telah dibuat dan dapat membedakan warna hitam putih sebagai jalur track. Penerapan metode fuzzy logic control telah digunakan pada robot. Semakin tinggi kecepatan robot dalam mengikuti garis maka robot menjadi mudah untuk keluar dari garis.

\section{SARAN}

Dari hasil penelitian ini masih terdapat beberapa kekurangan dan dimungkinkan untuk melakukan pengembangan lebih lanjut. Beberapa saran yang perlu penulis sampaikan adalah sebagai berikut: a) keadaan robot mengikuti garis hanya bisa dengan kondisi tikungan yang tidak tajam. Bila terdapat tikungan yang tajam maka memungkinkan robot untuk keluar line; b) Kemampuan robot menjaga keseimbangan hanya untuk bidang yang rata. Untuk penyempurnaan dapat dibuat arena yang mempunyai tanjakan.

\section{UCAPAN TERIMA KASIH}

Penulis mengucapkan terima kasih kepada STMIK Pontianak yang telah memberi dukungan financial terhadap penelitian ini.

\section{DAFTAR PUSTAKA}

[1] Sulistiyo, W., 2009, Desain dan Rancang Bangun Mobil Robot Penjejak Jalur dengan Algoritma Fuzzy, Orbith, No. 3, Vol. 5, hal. 431-439.

[2] Dwisaputra, I., Sulistijono, I. A., Nugraha, M. I., 2011, Two Wheels Balancing Line Tracer Robot Using Fuzzy Logic Control, The 13th Industrial Electronics Seminar 2011 (IES 2011), Electronic Engineering Polytechnic Institute of Surabaya (EEPIS), Surabaya, October 26 2011.

[3] Farooq, U., Amar, M., Asad, M. U., Abbas, G., Hanif, A., 2014, Fuzzy Logic Reasoning System for Line Following Robot, IACSIT International Journal of Engineering and Technology, No. 4, Vol. 6, Hal. 244-248.

[4] Perdue, D. J., Laurens, V., 2011, The Unofficial Lego(R) Mindstorms(R) NXT 2.0 Inventor's Guide, No Starch Press, Inc., San Francisco, California.

[5] Holland, J. M., 2004, Designing Autonomous Mobile Robot, Inside the Mind of an Intelligent Machine, Elsevier Inc, US America.

[6] Jatntzen, J., 2007, Foundation of Fuzzy Control, John Wiley and Sons Ltd, England. 